\title{
The "Rapid'Salmonella" Method: Estimation of the Limit of Detection for Salmonella Strains Typhimurium and Enteritidis Isolated from Frozen Poultry Meat
}

\author{
Tariq Hantash ${ }^{1,2}$, Maarten Nauta ${ }^{3}$, Mohammad N. S. Al-Sabi ${ }^{4}$, Walid Q. Al-ali ${ }^{5}$ \& Håkan Vigre ${ }^{1}$ \\ ${ }^{1}$ Division for Global Surveillance, Research Group for Genomic Epidemiology, National Food Institute, \\ Technical University of Denmark, Kemitorvet, 2800 Kgs. Lyngby, Denmark \\ ${ }^{2}$ Jordan Food and Drug Administration, Ahmed Al Kayed Al Qatishat St, Shafa Badran, P.O. Box: 11181, Postal \\ Code: 811951, Amman, Jordan \\ ${ }^{3}$ Research Group for Risk-Benefit, National Food Institute, Technical University of Denmark, Kemitorvet, \\ Building 201, 2800 Kgs. Lyngby, Denmark \\ ${ }^{4}$ Department of Microbiology and Parasitology, Faculty of Veterinary Medicine, King Faisal University, P.O. \\ 380 Ahsaa 31982, Saudi Arabia \\ ${ }^{5}$ Department of Epidemiology \& Biostatistics, Faculty of Public Health, Kuwait University, P.O. Box 24923 \\ Safat 13110, Kuwait \\ Correspondence: Tariq Hantash, Global Surveillance Department, National Food Institute, Technical University \\ of Denmark, Kemitorvet, Building 204, 2800 Kgs. Lyngby, Denmark.
}

Received: October 13, 2020

Accepted: November 25, 2020

Online Published: November 27, 2020

doi:10.5539/mas.v14n12p43

URL: https://doi.org/10.5539/mas.v14n12p43

\begin{abstract}
As a part of evaluation the surveillance system of Salmonella in frozen imported poultry meat into Jordan, we conducted a study to estimate the limit of detection $\left(\mathrm{LOD}_{50 \%}\right.$ and $\left.\mathrm{LOD}_{95 \%}\right)$ of Salmonella Typhimurium and Salmonella Enteritidis based on chromogenic media of Rapid'Salmonella method. Salmonella-free chicken meat samples was inoculated with 1 to $100 \mathrm{CFU}$ of 11 wild strains that originated from frozen imported poultry meat and 2 reference strains. In the experiment, the observed lowest concentration for Salmonella Typhimurium and Salmonella Enteritidis using Rapid'Salmonella method were from 1 to $50 \mathrm{CFU} / 25 \mathrm{~g}$. Based on these results, probability of detection (POD) curve was estimated according to the model described in EN ISO 16140-4. From the estimated POD functions, the $\mathrm{LOD}_{50 \%}$ and $\mathrm{LOD}_{95 \%}$ was determined for the Rapid'Salmonella method. The $\mathrm{LOD}_{50 \%}$ of the different strains varied from 0.9 to $21.2 \mathrm{CFU} / 25 \mathrm{~g}$. The two reference strains and 9 wild strains had a $\mathrm{LOD}_{50 \%}$ less than $2 \mathrm{CFU} / 25 \mathrm{~g}$, one wild strain of Salmonella Enteritidis had a LOD $50 \%$ of $6.8 \mathrm{CFU} / 25 \mathrm{~g}$ and another one had a $\mathrm{LOD}_{50 \%}$ of $21.2 \mathrm{CFU} / 25 \mathrm{~g}$. The majority of Salmonella strains has a $\mathrm{LOD}_{50 \%}$ of $1-4$ $\mathrm{CFU} / 25 \mathrm{~g}$ in poultry meat, but also that there are some Salmonella strains which will first be detected at 10 $\mathrm{CFU} / 25 \mathrm{~g}$ and higher.
\end{abstract}

Keywords: $\mathrm{LOD}_{50 \%}, \mathrm{LOD}_{95 \%}$, POD, poultry meat, Rapid'Salmonella, Salmonella Typhimurium, Salmonella Enteritidis, surveillance

\section{Introduction}

Non-Typhoidal Salmonella (NTS) including Salmonella Typhimurium and Enteritidis are the most frequent causes of foodborne salmonellosis in the Middle East and North Africa (MENA). In the MENA countries including Jordan, the presence of NTS strains Typhimurium and Enteritidis in domestic and imported poultry meat is one of the main concerns of the food safety authorities (Malaeb, Bizri, Ghosn, Berry, \& Musharrafieh, 2016; Nimri, Abu AL- Dahab, \& Batchoun, 2014; Osaili et al., 2014).

According to the Jordan Food and Drug Administration (JFDA) guidelines, all imported frozen poultry meat at customs ports requires a scheduled sampling to test for Salmonella strains Typhimurium and Enteritidis (Jordan Food and Drug Administration, 2015). From each batch, one sample is collected. A batch of poultry meat is equivalent to one type of product produced on a specific date in one establishment (Jordan Food and Drug Administration, 2015). Sample units are transported to the JFDA laboratories where $25 \mathrm{~g}$ is apportioned, thawed 
and analyzed according to the Rapid'Salmonella method (Bio-Rad, Marnes-la-Coquette, France). This method was introduced in 2015 as an alternative to the reference method "ISO 6579:2017" for rapid detection of Salmonella spp. including strains of Salmonella Typhimurium and Enteritidis and followed by real time (RT)-PCR (Maurischat, Baumann, Martin, \& Malorny, 2015) for confirmation and identification.

The Rapid'Salmonella method has been certified by Association Francaise de Normalisation (AFNOR), Nordic System for Validation of Alternative Microbiological Methods (NordVal), and Association of Official Analytical Chemist (AOAC) as alternative to reference method "ISO 6579:2017", for the detection of Salmonella spp., according to the ISO 16140 protocol (ADRIA Development, 2017; Anynomous, 2016, 2017; Lauer, 2009; Norli \& Nielsen, 2018).

In 2015, with the use of Rapid'Salmonella method, 29 batches of poultry meat (representing approximately 200 tons) out of 3,109 examined (representing approximately 50,000 tons) were rejected at the Jordan border because they were found positive for Salmonella strains Typhimurium and Enteritidis. However, it is expected that a number of contaminated batches of poultry meat were not detected by the method used. The likelihood to detect a contaminated batch depends on the actual occurrence of Salmonella in the batch (prevalence of contaminated items and concentration of Salmonella in those items) and limit of detection (LOD) of laboratory method used. This likelihood can be described by the probability of detection (POD) function (Wilrich \& Wilrlich, 2009), and is a useful quantitative measurement of the overall performance of a surveillance program.

However, the LODs of the Rapid'Salmonella method for Salmonella strains Typhimurium and Enteritidis in frozen poultry contaminated with relevant field strains for poultry meat imported to Jordan has never been studied.

The objective of this study was to determine the lowest number of cells of different Salmonella Typhimurium and Enteritidis strains isolated from imported frozen poultry meat that can be detected using the commercial laboratory method Rapid'Salmonella. This was done in a spiking experiment using a serial dilution of concentration of several field strains. Subsequently, a probability function of detection (POD) was fitted to the observed LOD values, from where $\mathrm{LOD}_{50 \%}$ and $\mathrm{LOD}_{95 \%}$ was determined.

The overall aim of the border control is to protect the consumers against salmonellosis attributable to imported poultry meat. The POD functions estimated in this study will be important input for subsequent assessment of the border control using quantitative risk assessment. In addition, the experimental setup and the estimation of the POD function can be used when assessing the effect of improved laboratory methods and sampling strategies used at border control.

\section{Method}

In the spiking experiment known numbers of different strains of Salmonella Typhimurium and Enteritidis were duplicate inoculated on Salmonella-free chicken meat samples, and subsequently the samples were analyzed using the Rapid'Salmonella method for detection. The observed data from the spiking experiment (concentration and positive/negative) was used for estimating the $\mathrm{POD}, \mathrm{LOD}_{50 \%}$, and $\mathrm{LOD}_{95 \%}$.

\subsection{Chicken Meat Samples}

The Salmonella-free chicken meat samples (whole chicken carcasses and boneless chicken breast fillet with skin) used in this study were equally brought from Denmark and Brazil in 2018. The European Commission regulation 2018/307 declared Danish broiler meat as Salmonella-free. Before conducting the study, the Brazilian chicken meat samples were collected from a batch of boneless breast fillet chicken meat with skin of 2.5-kg packages. From this batch, five samples of $25 \mathrm{~g}$ were collected and tested for the presence of Salmonella using the ISO 6579:2017 method (Anynomous, 2017). All five samples were negative.

The Salmonella-free chicken meat was cut into 25 -g portions representing samples, and these samples $(n=132)$ were stored at $-18^{\circ} \mathrm{C}$ for a maximum of 30 days. The samples were thawed at $4^{\circ} \mathrm{C}$ for $24 \mathrm{~h}$ before use.

\subsection{Bacterial Strains and Inoculum Preparation}

The samples were spiked with 13 strains of Salmonella Typhimurium and Salmonella Enteritidis from the JFDA surveillance collection (see Table A1 in Appendix). These strains were grown in nutrient broth (Oxoid, Basingstoke, UK) and incubated at $37^{\circ} \mathrm{C} \pm 1{ }^{\circ} \mathrm{C}$ for $24 \mathrm{~h}$ to obtain expected bacterial concentrations $10^{9} \mathrm{CFU} / \mathrm{ml}$. Using 10-ml volumes, serial dilutions established five levels with expected bacterial concentrations of 100, 50, 10,5 , and $1 \mathrm{CFU} / \mathrm{ml}$. The number of cells in each established level of inoculation were enumerated and recorded to calculate the initial bacterial concentrations as described below. 


\subsection{Total Count of Inocula}

One $\mathrm{ml}$ of each of the above five levels of established serial dilutions was poured on duplicate plates of aerobic Plate Count Agar (PCA, Scharlau, Barcelona, Spain). These two plates were used for counting the total count of the bacteria after incubation at $37^{\circ} \mathrm{C} \pm 1{ }^{\circ} \mathrm{C}$ for $48 \mathrm{~h}$. Colony counts from $0-250 \mathrm{CFU} /$ plate were used for estimating the total viable count. The same person throughout the study performed the counting. The estimated total count was used to determine the apparent concentration of Salmonella in the 25-g of spiked samples (see Table 1). The total count of bacterial concentration in each inoculum was estimated according to the formula:

$$
\text { Total count }(\mathrm{CFU} / \mathrm{ml})=\frac{\sum_{\text {plate }=1}^{\text {plate }=} \text { number of enumarated colonies }[\mathrm{CFU}]}{\sum_{\text {plate }=1}^{\text {plate }=1}(\text { dilution } \text { factor } \times \text { volume plated }[\mathrm{ml}])}
$$

Note. Plate $=1 \ldots \mathrm{n}$ is the plates with colony numbers between $0-250 \mathrm{CFU}$ for a specific strain.

\subsection{Spiking Samples}

For each dilution and strain, we performed duplicate spikes on two separate chicken meat samples. Each $25-\mathrm{g}$ sample was spiked individually with $1 \mathrm{ml}$ of each of the 13 strains of Salmonella Typhimurium and Salmonella Enteritidis with the established five levels of expected bacterial concentrations $100,50,10,5$, and $1 \mathrm{CFU} / 25 \mathrm{~g}$. In addition, two samples were not spiked and served as negative controls. All samples were analyzed for Salmonella presence as described below.

\subsection{Laboratory Procedure}

The method "Rapid'Salmonella" was used in this study to detect the presence of Salmonella in the spiked samples. Buffered Peptone Water (225 ml, BPW, Oxoid, Basingstoke, UK) was added to each of the spiked 25-g sample portions in a stomacher bag along with $1 \mathrm{ml}$ of Rapid'Salmonella capsule-prepared solution (Bio-Rad, Marnes-la-Coquette, France). After homogenization in a stomacher device (BagMixer, Interscience, Saint-Nom-la-Bretèche, France) at high speed for $1 \mathrm{~min}$, samples were incubated at $41.5^{\circ} \mathrm{C} \pm 1^{\circ} \mathrm{C}$ for $20 \mathrm{~h}$. One hundred $\mu 1$ of each incubated samples were streaked onto Rapid'Salmonella chromogenic agar plates (Bio-Rad, Marnes-la-Coquette, France). Cultured plates were incubated at $37^{\circ} \mathrm{C} \pm 1{ }^{\circ} \mathrm{C}$ for $24 \mathrm{~h}$. Suspected colonies were picked, streaked to Nutrient Agar (NA, Oxoid, Basingstoke, UK) and incubated at $37^{\circ} \mathrm{C} \pm 1^{\circ} \mathrm{C}$ for $24 \mathrm{~h}$ to control for non-specific growth and as a measurement of purity. Pure colonies were picked for presumptive Salmonella spp. detection and confirmation via Salmonella polyvalent O (somatic) antiserum (Remel, Dartford, UK), as an agglutination test. Identification of Salmonella strains Typhimurium and Enteritidis were carried out using real time (RT)-PCR (Maurischat et al., 2015).

Table 1. Rapid'Salmonella method detection results in chicken samples artificially contaminated with Salmonella strains

\begin{tabular}{|c|c|c|c|c|c|c|c|c|c|c|c|c|c|}
\hline \multirow{3}{*}{$\begin{array}{l}\text { Expected } \\
\text { Inoculum } \\
\text { Concentration }\end{array}$} & \multirow{2}{*}{$\begin{array}{l}S . \text { Typhimurium } \\
\text { ATCC } 12048\end{array}$} & \multirow{2}{*}{$\begin{array}{l}\text { S.Enteritidis } \\
\text { ATCC } 13076\end{array}$} & \multicolumn{5}{|c|}{$S$.Typhimurium $(n=7)$} & \multicolumn{6}{|c|}{ S.Enteritidis $(n=4)$} \\
\hline & & & 1 & 2 & 3 & 4 & 5 & 6 & 7 & 1 & 2 & 3 & 4 \\
\hline & \multicolumn{13}{|c|}{ Detection $\left({ }^{a} 0,1,2 /{ }^{b} 0,1,2\right)$} \\
\hline 100 & $2 / 0$ & $2 / 2$ & $2 / 0$ & $2 / 0$ & $2 / 0$ & $2 / 0$ & $2 / 0$ & $2 / 0$ & $2 / 0$ & $2 / 0$ & $2 / 0$ & $2 / 0$ & $2 / 0$ \\
\hline 50 & $2 / 0$ & $2 / 2$ & $2 / 0$ & $2 / 0$ & $2 / 0$ & $2 / 0$ & $2 / 0$ & $2 / 0$ & $2 / 0$ & $2 / 0$ & $2 / 0$ & $2 / 0$ & $2 / 0$ \\
\hline 10 & $2 / 0$ & $2 / 2$ & $2 / 0$ & $2 / 0$ & $2 / 0$ & $2 / 0$ & $2 / 0$ & $2 / 0$ & $2 / 0$ & $2 / 0$ & $2 / 0$ & $2 / 0$ & $0 / 2$ \\
\hline 5 & $2 / 0$ & $2 / 2$ & $2 / 0$ & $2 / 0$ & $2 / 0$ & $2 / 0$ & $2 / 0$ & $2 / 0$ & $2 / 0$ & $2 / 0$ & $0 / 2$ & $2 / 0$ & $0 / 2$ \\
\hline 1 & $1 / 1$ & $1 / 1$ & $0 / 2$ & $0 / 2$ & $1 / 1$ & $1 / 1$ & $1 / 1$ & $1 / 1$ & $1 / 1$ & $0 / 2$ & $0 / 2$ & $0 / 2$ & $0 / 2$ \\
\hline
\end{tabular}

Note. ${ }^{a}=\mathrm{a}$ number of samples results indicate Salmonella strain presence; ${ }^{b}=\mathrm{a}$ number of samples results indicate Salmonella strain absence

\subsection{Determining the Limit of Detection}

The observed lowest concetration that was detected from the inoculation experiment by comparing the observed results in terms of presence/absence of growth with the number of Salmonella in the 25-g spiked samples. We used two measures for "the number of Salmonella in the spiked samples": the number based on the total count as calculated in formula 1, and the expected number of bacteria based on the dilution series. Based on the qualitative results, a probability function for detecting the strain at different concetrations $(d)$ was estimated under the statistical analysis was carried out by application of the EXCEL sheet PODLOD.xls (Wilrich \& Wilrlich, 2009). This model described in EN ISO 16140-4, using a program in Excel, freely available on the Internet, version 9, dated 2017-09-23 (Anonymous, 2016). The $\mathrm{LOD}_{p}$ was defined as the lowest contamination 
level (CFU/25 g) where the Rapid'Salmonella method is positive with specified probability, $p$.

Based on the function, the $\mathrm{LOD}_{50 \%}$ and $\mathrm{LOD}_{95 \%}$ was calculated for each strain, specifying the lowest concentration of Salmonella in the meat matrix that can be detected with a probability of $50 \%$ or $95 \%$, respectively. The $\mathrm{LOD}_{50 \%}$ and $\mathrm{LOD}_{95 \%}$ with confidence limits for each strain were calculated (Table 2 and Table 3 ). Finally, The obtained estimates is used to express the POD function as $p(d)$ of wide range of assumed known contamination $d$ according to inoculated levels from 0 to $100 \mathrm{CFU} / 25 \mathrm{~g}$, and as the following formula:

$$
p(d)=1-\exp \left(-A_{0} F_{i} d\right)
$$

Where $A_{0}$ is the sample size $=25-\mathrm{g}, F i$ is the matrix effect that is $<1$ (estimated the deviation of the POD curve from the ideal POD curve that has estimated LOD $=1$ by application of the EXCEL sheet PODLOD.xls (Wilrich \& Wilrlich, 2009)), and $d$ the contamination in CFU/25 $\mathrm{g}$.

\section{Results and Discussion}

\subsection{Concentrations of Bacterial Inocula}

The validity of the estimted $\mathrm{LOD}_{p}$ is strongly depending on that the number of bacteria in the inocula is known. In this study, we performed the estimation of the probability function using both expected number of bacteria and apparent number of bacteria. The total counts of bacteria were about $50 \%-100 \%$ of the expected bacterial concentration that was established for Salmonella pure cultures and spiked chicken meat samples (see Table 1). The relatively low apparent counts may be due to bacterial clustering features, and some organisms may have been stressed and died during handling of the sample (Capozzi, Fiocco, Amodio, Gallone, \& Spano, 2009; Sutton, 2011). Most likely, the actual bacterial concentrations in this study were in-between the total apparent concentrations and the expected bacterial concentrations based on the dilution series. Accordingly, the observed lowest concentration was assigned to both apparent and expected bacterial concentration. The differences bewteen $\mathrm{LOD}_{p}$ based on apparent and expected bacterial concentration were negligible (see Table A3 and Table A4 in Appendix).

\subsection{Limit of Detections}

The observed lowest concentration for Salmonella Typhimurium and Salmonella Enteritidis using Rapid'Salmonella method were from 1 to $50 \mathrm{CFU} / 25 \mathrm{~g}$ for spiked chicken meat samples (Table 1). The estimatd $\mathrm{LOD}_{50 \%}$ for Salmonella Typhimurium were from 0.9 to $1.8 \mathrm{CFU} / 25 \mathrm{~g}$ (Table 2) and for Salmonella Enteritidis were from 0.8 to $21.2 \mathrm{CFU} / 25 \mathrm{~g}$ (Table 3). The $\mathrm{LOD}_{95 \%}$ for Salmonella Typhimurium were from 3.7 to 7.6 CFU/25 g (Table 2) and for Salmonella Enteritidis were from 3.7 to $91.7 \mathrm{CFU} / 25 \mathrm{~g}$ (Table 3). The $\mathrm{LOD}_{50 \%}$ combined results for Salmonella Typhimurium and Salmonella Enteritidis were 1.1 CFU/25 g (95\% CI: 0.6-1.8 $\mathrm{CFU} / 25 \mathrm{~g}$ ) and $4.2 \mathrm{CFU} / 25 \mathrm{~g}(95 \% \mathrm{CI}: 2.3-7.3 \mathrm{CFU} / 25 \mathrm{~g}$ ), respectively, indicating a significant difference in general between Salmonella Typhimurium and Salmonella Enteritidis detection level.

Table 2. Expected count of Salmonella Typhimurium calculation of $\mathrm{LOD}_{50 \%}$ in $\mathrm{CFU} / 25 \mathrm{~g}$

\begin{tabular}{lllll}
\hline Salmonella strains & LOD $_{50 \%}$ & $\begin{array}{c}\text { confidence interval } \\
(95 \%)\end{array}$ & LOD $_{95 \%}$ & $\begin{array}{l}\text { confidence interval } \\
(95 \%)\end{array}$ \\
\hline Salmonella Typhimurium ATCC & 0.9 & $(0.2-4.0)$ & 3.7 & $(0.8-17.4)$ \\
Salmonella Typhimurium isolate no. 1 & 1.8 & $(0.5-6.2)$ & 7.6 & $(2.1-26.8)$ \\
Salmonella Typhimurium isolate no. 2 & 1.8 & $(0.5-6.2)$ & 7.6 & $(2.1-26.8)$ \\
Salmonella Typhimurium isolate no. 3 & 0.9 & $(0.2-4.0)$ & 3.7 & $(0.8-17.4)$ \\
Salmonella Typhimurium isolate no. 4 & 0.9 & $(0.2-4.0)$ & 3.7 & $(0.8-17.4)$ \\
Salmonella Typhimurium isolate no. 5 & 0.9 & $(0.2-4.0)$ & 3.7 & $(0.8-17.4)$ \\
Salmonella Typhimurium isolate no. 6 & 0.9 & $(0.2-4.0)$ & 3.7 & $(0.8-17.4)$ \\
Salmonella Typhimurium isolate no. 7 & 0.9 & $(0.2-4.0)$ & 3.7 & $(0.8-17.4)$ \\
\hline Combined results & 1.1 & $(0.6-1.8)$ & 4.6 & $(2.8-7.7)$ \\
\hline
\end{tabular}


Table 3. Expected count of Salmonella Entritidis calculation of $\mathrm{LOD}_{50 \%}$ in $\mathrm{CFU} / 25 \mathrm{~g}$

\begin{tabular}{lllll}
\hline Salmonella strains & LOD $_{50 \%}$ & $\begin{array}{c}\text { confidence interval } \\
(95 \%)\end{array}$ & $\begin{array}{l}\text { LOD }_{95 \%} \\
\text { confidence interval } \\
(95 \%)\end{array}$ \\
\hline Salmonella Enteritidis ATCC & 0.9 & $(0.2-4.0)$ & 3.7 & $(0.8-17.4)$ \\
Salmonella Enteritidis isolate no. 1 & 1.8 & $(0.5-6.2)$ & 7.6 & $(2.1-26.8)$ \\
Salmonella Enteritidis isolate no. 2 & 6.8 & $(1.9-24.3)$ & 29.5 & $(8.3-105.2)$ \\
Salmonella Enteritidis isolate no. 3 & 21.2 & $(6.7-66.4)$ & 91.5 & $(29.1-287.1)$ \\
Salmonella Enteritidis isolate no. 4 & 1.8 & $(0.5-6.2)$ & 7.6 & $(2.1-26.8)$ \\
\hline Combined results & 4.2 & $(2.3-7.3)$ & 18.4 & $(10.6-31.7)$
\end{tabular}

The laboratory American Type Culture Collection (ATCC) strains have the lowest detection level (Table 1). The reason for this is probably because these strains are fit to culture under laboratory conditions (de Moraes et al., 2016). Some wild strains have the same detection level as the laboratory ATCC strainsi, whereas the $\operatorname{LOD}_{p}$ of some wild strains were higher. The highest $\mathrm{LOD}_{50 \%}(21.2 \mathrm{CFU} / 25 \mathrm{~g})$ was obtained from an isolate of Salmonella Enteritidis sampled from imported chicken legs. A part of the observed variation in values of $\mathrm{LOD}_{p}$ is probably due to a random variation between experiments, but the results indicate that the $\mathrm{LOD}_{p}$ is varying between Salmonella strains.

The estimated POD of different concentrations of Salmonella Typhimurium and Salmonella Enteritidis giving $d$ values of $\mathrm{LOD}_{p}$ using the Rapid'Salmonella method to detect Salmonella strains in imported poultry meat to Jordan is presented in figure 1 . Given by the estimated POD curve, the lowest $\mathrm{LOD}_{50 \%}$ was $1 \mathrm{CFU} / 25 \mathrm{~g} \mathrm{(95 \%} \mathrm{CI:}$ 0.2-4.0 CFU/25 g); and 85\% of studied Salmonella strains has a LOD $50 \%$ equal or lower than $2 \mathrm{CFU} / 25 \mathrm{~g}(95 \%$ CI: 0.5-6.2 CFU/25 g). The results shows that the majority of these Salmonella strains will be detected at concentrations of few cells that around 1-5 CFU/25 g, but there is also some Salmonella strains which will first be detected at concentrations around $50 \mathrm{CFU} / 25 \mathrm{~g}$ (Table 1).

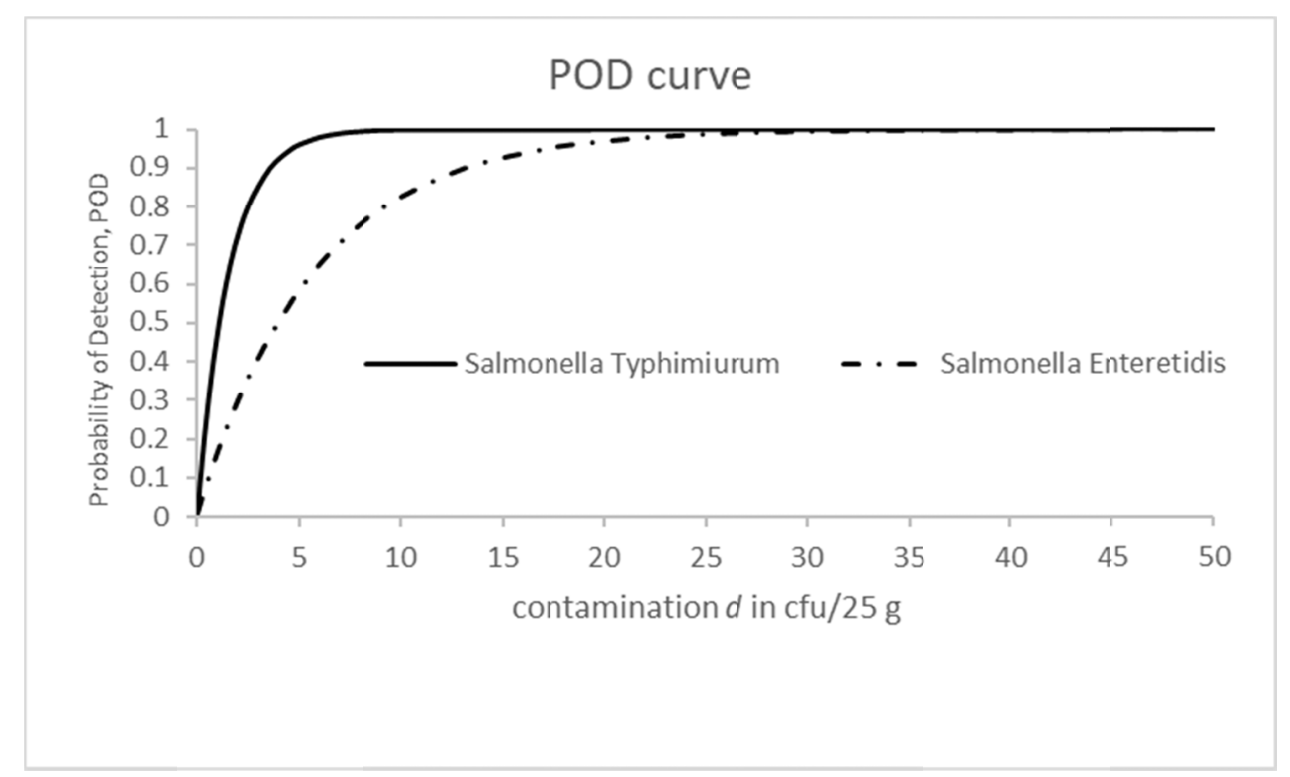

Figure 1. The estimated Probability of Detection (POD) for different concentrations of studied Salmonella strains in poultry meat. The solid line represent of the general POD for seven strains of Salmonella Typhimiurum and dashed line for four Salmonella Enteretidis strains

That the Rapid'Salmonella method had different observed detection limits for different Salmonella strains recovered from examined poultry meat samples can be explained by the fact that the strains has different growth rates during the enrichment phase (Löfström, Hansen, Mansdal, \& Hoorfar, 2012). The actual detection method afterwards depends on that enrichment phase has resulted in a detectable concentration. The bacterial growth rate during the enrichment phase depends on characteristics of the strain of Salmonella and stress introduced by storage conditions, growth inhibitors from the meat and competing microflora (Lammerding, 2006).

The use of non-frozen isolates in our experiment might result in unrealistic low detection levels compared with 
realistic situations where the bacteria in the imported meat has been frozen, and thereby, they are stressed and injured causing a lag in the growth. However, due to controlled conditions in the enrichment, the lag-phase can be assumed to last for only 1-2 h (Oscar, 1998), which is equivalent with 3-6 generations of growth for Salmonella in optimal growth conditions in broth at $37{ }^{\circ} \mathrm{C}$, assuming a generation time of 20-30 min. The loss of 3-6 generations due to lag-phase is proportionally a low number compared with the approximately 100 generations that can be expected for Salmonella in 18-20 h given experimental conditions (Oscar, 1998). Thereby, the effect of using non-frozen isolates on the estimated $\operatorname{LOD}_{p}$ is expected to be minor. Contemporary, by not freezing the samples after spiking, we know how many viable bacteria that are actually present in the sample, which strengthens the validity of the estimated $\mathrm{LOD}_{p}$.

In the spiking experiment, one strain of each Salmonella Typhimurium and Enteritidis from the ATCC and 11 from the JFDA's isolates in imported frozen poultry meat were used. Even though, the estimated $\mathrm{LOD}_{p}$ cannot be generalized to all strains of Salmonella in all types of food items, the estimated $\mathrm{LOD}_{p}$ in this study indicate the $\mathrm{LOD}_{p}$ that can be expected when using of Rapid 'Salmonella method at the border control of frozen poultry meat.

In the spiking study performed by AFNOR, they used 152 Salmonella strains at contamination levels between 5-25 CFU/sample, but only 5 of those represent Salmonella Typhimurium and Enteritidis spiked into poultry meat (ADRIA Development, 2017). In our study, 12 out of 13 Salmonella strains are at observed lowest concentration $\leqslant 5 \mathrm{CFU} / 25 \mathrm{~g}$, which is in alignment with AFNOR spiking study finding approximately $70 \%$ of tested Salmonella strains with the same observed lowest concentration (ADRIA Development, 2017). In addition, they compare the performances of reference method and alternative method by estimating $\mathrm{LOD}_{50 \%}$, which were between 0.1-5.6 and 0.1-1.8 CFU/25 g, respectively (Norli \& Nielsen, 2018). In our study, the $\mathrm{LOD}_{50 \%}$ for Salmonella Typhimurium and Salmonella Enteritidis were between 0.6-7.3 CFU/25 g, which is in alignment with AFNOR validation certification (Norli \& Nielsen, 2018).

There are many surveillance programs that employ rapid immunoassays and PCR methods instead of conventional culture methods for detecting Salmonella in poultry meat to cope with the enormous volume of samples (Brooks, Lutze-Wallace, Devenish, Elmufti, \& Burke, 2012; Cheung \& Kam, 2012; Hitchins, 2012; Tomás Fornés, McMahon, Moulin, \& Klijn, 2017). The observed detection level of the conventional pre-enrichment step that directly coupled with the PCR methods is 100-200 CFU/25 g of Salmonella Typhimurium and Enteritidis in poultry meat (Mohd Afendy \& Son, 2015; Paião et al., 2013; Siala et al., 2017). Compared to this, the Rapid'Salmonella method can be considered relatively sensitive for most strains of Salmonella Typhimurium and Enteritidis.

\section{Conclusion}

In the spiking experiment, we found that the observed level of detecting Salmonella Typhimurium and Salmonella Enteritidis from poultry meat using the commercial Rapid'Salmonella method varies between 1 and $50 \mathrm{CFU} / 25 \mathrm{~g}$. The most natuarally wild Salmonella strains and laboratory-adapted ones have LOD $_{50 \%}$ between 1 and $4 \mathrm{CFU} / 25 \mathrm{~g}$. However, due to the studied Salmonella strains are limited in numbers and serotypes, their results can't be generalized to all Salmonella spp. without caution. Future studies should focus on including more serotypes that representing different countries of origin and interlaboratory comparison for robustness.

Referring to the POD curves in figure 1, it can be concluded that most studied Salmonella strains has a $\mathrm{LOD}_{50 \%}$ of 1-4 CFU/25 g in poultry meat, but also that there are some Salmonella strains which will be detected at concentrations around $10 \mathrm{CFU} / 25 \mathrm{~g}$ and higher. The concetration in the matrix, which gives a $95 \%$ likelihood for detection $\left(\mathrm{LOD}_{95 \%}\right)$ was for most Salmonella Typhimiurm strains around $5 \mathrm{CFU} / 25 \mathrm{~g}$, whereas for most Salmonella Enteretidis strains it was around $50 \mathrm{CFU} / 25 \mathrm{~g}$.

This study is the intial step in evaluating and optimizing current Salmonella surveillance of poultry meat in the MENA region.

\section{Acknowledgments}

We acknowledge Dr. Rajab Al-Najar, and Ahmad Ismael, Directorate of Food, JFDA, Amman, Jordan, for providing us with the extensive laboratory technical work and advice during the research, and the Islamic Development Bank Merit Scholarship Program supported this research.

\section{References}

ADRIA Development. (2017). NF Validation RAPID'Salmonella method for Salmonella detection in human food, feed and environmental samples. Retrieved from https://nf-validation.afnor.org//en/wp-content/uploads/sites/2/2014/03/Synt-BRD-07-11-12-05_en.pdf 
Anonymous. (2016). Microbiology of the food chain - Method validation - Part 2: Protocol for the validation of alternative (proprietary) methods against a reference method (ISO 16140-2:2016). (2016). Retrieved from http://standards.iso.org/iso/\%0A16140

Anynomous. (2017). Microbiology of the food chain - Horizontal method for the detection, enumeration and serotyping of Salmonella - Part 1: Detection of Salmonella spp. (ISO 6579-1:2017). Retrieved from http://standards.iso.org/iso/\%0A6579-1

Brooks, B. W., Lutze-Wallace, C. L., Devenish, J., Elmufti, M., \& Burke, T. (2012). Development of an antigen-capture monoclonal antibody-based enzyme-linked immunosorbent assay and comparison with culture for detection of Salmonella enterica serovar Enteritidis in poultry hatchery environmental samples. Journal of Veterinary Diagnostic Investigation, 24(3), 509-515. https://doi.org/10.1177/1040638712441606

Capozzi, V., Fiocco, D., Amodio, M. L., Gallone, A., \& Spano, G. (2009). Bacterial stressors in minimally processed food. International Journal of Molecular Sciences, 10, 3076-3105. https://doi.org/10.3390/ijms10073076

Cheung, P. Y., \& Kam, K. M. (2012). Salmonella in food surveillance: PCR, immunoassays, and other rapid detection and quantification methods. Food Research International, 45(2), 802-808. https://doi.org/10.1016/j.foodres.2011.12.001

de Moraes, M. H., Chapin, T. K., Ginn, A., Wright, A. C., Parker, K., Hoffman, C., ... Teplitski, M. (2016). Development of an Avirulent Salmonella Surrogate for Modeling Pathogen Behavior in Pre- and Postharvest Environments. Applied and Environmental Microbiology, 82(14), 4100-4111. https://doi.org/10.1128/AEM.00898-16

Hitchins, A. D. (2012). A meta-analytical estimation of the detection limits of methods for Salmonella in food. Food Research International, 45(2), 1065-1071. https://doi.org/10.1016/j.foodres.2011.02.055

Jordan Food and Drug Administration. (2015). Anual report (Vol. 3). Retrieved from http:/www.jfda.jo/EchoBusV3.0/SystemAssets/PDF/AR/AnnualReports/AnnualReport2015.pdf/

Lammerding, A. M. (2006). Modeling and risk assessment for Salmonella in meat and poultry. Journal of AOAC International, 89(2), 543-552. https://doi.org/10.1093/jaoac/89.2.543

Lauer, W. F. (2009). RAPID'Salmonella chromogenic medium. Performance Tested Method 050701. Journal of Aoac International, $\quad 92(6) . \quad$ Retrieved from https://findit.dtu.dk/en/catalog/111048369?single_revert=\%2Fen\%2Fcatalog\%3Fq\%3DRAPID\%2527Salm onella\%2Bchromogenic\%2Bmedium.\%2BPerformance\%2BTested\%2BMethod\%2B050701.\%26show_sin gle $\% 3$ Doff $\% 26$ utf $\% 3$ D $\% 25 \mathrm{E} 2 \% 259 \mathrm{C} \% 2593$

Löfström, C., Hansen, F., Mansdal, S., \& Hoorfar, J. (2012). Detection of Salmonella in Meat: Comparative and Interlaboratory Validation of a Noncomplex and Cost-Effective Pre-PCR Protocol. Journal of AOAC International, 95(1), 100-104. https://doi.org/10.5740/jaoacint.11-093

Malaeb, M., Bizri, A. R., Ghosn, N., Berry, A., \& Musharrafieh, U. (2016). Salmonella burden in Lebanon. Epidemiology and Infection, 144(8), 1761-1769. https://doi.org/10.1017/S0950268815003076

Maurischat, S., Baumann, B., Martin, A., \& Malorny, B. (2015). Rapid detection and specific differentiation of Salmonella enterica subsp. enterica Enteritidis, Typhimurium and its monophasic variant 4,[5],12:i:- by real-time multiplex PCR. International Journal of Food Microbiology, 193, 8-14. https://doi.org/10.1016/j.ijfoodmicro.2014.10.004

Mohd Afendy, A. T., \& Son, R. (2015). Pre-enrichment effect on PCR Detection of Salmonella Enteritidis in artificially-contaminated raw chicken meat. International Food Research Journal, 22(6), 2571-2576.

Nimri, L., Abu AL- Dahab, F., \& Batchoun, R. (2014). Foodborne bacterial pathogens recovered from contaminated shawarma meat in northern Jordan. The Journal of Infection in Developing Countries, 8(11), 1407-1414. https://doi.org/10.3855/jidc.4368

Norli, H. S., \& Nielsen, N. S. (2018). NordVal International Certificate RAPID'Salmonella method, short protocol. Retrieved

from https://www.nmkl.org/dokumenter/nordval/Sertifikater/NordVal-certificate-032-BioRad-Rapid-Salmonella2018.pdf

Osaili, T. M., Al-Nabulsi, A. A., Shaker, R. R., Jaradat, Z. W., Taha, M., Al-Kherasha, M., ... Holley, R. (2014). Prevalence of Salmonella serovars, Listeria monocytogenes, and Escherichia coli O157:H7 in 
Mediterranean ready-to-eat meat products in Jordan. Journal of Food Protection, 77(1), 106-111. https://doi.org/10.4315/0362-028X.JFP-13-049

Oscar, T. P. (1998). Growth Kinetics of Salmonella Isolates in a Laboratory Medium as Affected by Isolate and Holding Temperature $\dagger$. Journal of Food Protection, 61(8), 964-968. https://doi.org/10.4315/0362-028X-61.8.964

Paião, F. G., Arisitides, L. G. A., Murate, L. S., Vilas-Bôas, G. T., Vilas-Boas, L. A., \& Shimokomaki, M. (2013). Detection of Salmonella spp, Salmonella Enteritidis and Typhimurium in naturally infected broiler chickens by a multiplex PCR-based assay. Brazilian Journal of Microbiology, 44(1), 37-41. https://doi.org/10.1590/S1517-83822013005000002

Siala, M., Barbana, A., Smaoui, S., Hachicha, S., Marouane, C., Kammoun, S., ... Messadi-Akrout, F. (2017). Screening and detecting Salmonella in different food matrices in Southern Tunisia using a combined enrichment/real-time PCR method: Correlation with conventional culture method. Frontiers in Microbiology, 8(DEC). https://doi.org/10.3389/fmicb.2017.02416

Sutton, S. (2011). Accuracy of Plate Counts. Journal of Validation Technology, 17(3), 42-46. https://doi.org/10.1016/j.fm.2005.01.010

Tomás Fornés, D., McMahon, W., Moulin, J., \& Klijn, A. (2017). Validation of test portion pooling for Salmonella spp. detection in foods. International Journal of Food Microbiology, 245, 13-21. https://doi.org/10.1016/j.ijfoodmicro.2017.01.005

Wilrich, C., \& Wilrlich, P.-T. (2009). Estimation of the POD function and the LOD of a binary microbiological measurement method from an interlaboratory experiment. Journal of AOAC International, 92(6), 1763-1772. https://doi.org/10.5740/jaoacint.18-0412 


\section{Appendix}

Table A1. Salmonella strains Typhimurium and Enteritidis used for Inoculation

\begin{tabular}{|c|c|}
\hline Inoculating organism & Source \\
\hline S.Typhimurium $(\mathrm{n}=1)$ & $\mathrm{ATCC}^{\circledR a} 12048$ \\
\hline S.Enteritidis $(\mathrm{n}=1)$ & $\mathrm{ATCC}^{\circledR} 13076$ \\
\hline S. Typhimurium $(\mathrm{n}=7)$ & Chicken Breast fillet, Chicken Mechanically deboned meat \\
\hline S.Enteritidis $(\mathrm{n}=4)$ & Chicken legs, boneless chicken carcass \\
\hline
\end{tabular}

Note. ${ }^{a}=$ ATCC, American Type Culture Collection

Table A2. Estimated count of Salmonella Typhimurium strains calculation of $\mathrm{LOD}_{50 \%}$ in $\mathrm{CFU} / 25 \mathrm{~g}$

\begin{tabular}{lcccc}
\hline Salmonella strains & LOD $_{50 \%}$ & $\begin{array}{c}\text { confidence interval } \\
(95 \%)\end{array}$ & $\begin{array}{c}\text { LOD }_{95 \%} \\
\text { confidence interval } \\
(95 \%)\end{array}$ \\
\hline Salmonella Typhimurium ATCC & 6.7 & $(1.5-32.3)$ & 29.8 & $(6.4-139.5)$ \\
Salmonella Typhimurium isolate no. 1 & 1.7 & $(0.5-6.2)$ & 7.6 & $(2.1-26.8)$ \\
Salmonella Typhimurium isolate no, 2 & 1.7 & $(0.5-6.2)$ & 7.6 & $(2.1-26.8)$ \\
Salmonella Typhimurium isolate no. 3 & 0.8 & $(0.2-4.0)$ & 3.7 & $(0.8-17.4)$ \\
Salmonella Typhimurium isolate no. 4 & 0.8 & $(0.2-4.0)$ & 3.7 & $(0.8-17.4)$ \\
Salmonella Typhimurium isolate no. 5 & 0.7 & $(0.1-3.2)$ & 3.0 & $(0.6-14)$ \\
Salmonella Typhimurium isolate no. 6 & 0.3 & $(0.1-1.6)$ & 1.5 & $(0.3-7)$ \\
Salmonella Typhimurium isolate no. 7 & 0.3 & $(0.1-1.3)$ & 1.2 & $(0.3-5.8)$ \\
\hline Combined results & 1.1 & $(0.7-1.9)$ & 5.0 & $(3.0-8.2)$ \\
\hline
\end{tabular}

Table A3. Estimated count of Salmonella Eneteritidis calculation of $\mathrm{LOD}_{50 \%}$ in CFU/25 $\mathrm{g}$

\begin{tabular}{|c|c|c|c|c|}
\hline Salmonella strains & $\mathrm{LOD}_{50 \%}$ & $\begin{array}{l}\text { confidence interval } \\
\qquad(95 \%)\end{array}$ & $\mathrm{LOD}_{95 \%}$ & $\begin{array}{l}\text { confidence interval } \\
\quad(95 \%)\end{array}$ \\
\hline Salmonella Enteritidis ATCC & 6.9 & $(1.5-32.3)$ & 29.8 & $(6.4-139.5)$ \\
\hline Salmonella Enteritidis isolate no. 1 & 3.0 & $(0.8-10.5)$ & 12.9 & $(3.6-45.5)$ \\
\hline Salmonella Enteritidis isolate no, 2 & 7.5 & $(2.1-26.8)$ & 32.5 & $(9.1-115.7)$ \\
\hline Salmonella Enteritidis isolate no. 3 & 7.0 & $(2.2-21.9)$ & 30.2 & $(9.6-94.7)$ \\
\hline Salmonella Enteritidis isolate no. 4 & 0.8 & $(0.2-2.7)$ & 3.3 & $(0.9-11.8)$ \\
\hline Combined results & 4.1 & $(2.3-7.3)$ & 17.8 & $(10.0-31.7)$ \\
\hline
\end{tabular}

\section{Copyrights}

Copyright for this article is retained by the author(s), with first publication rights granted to the journal.

This is an open-access article distributed under the terms and conditions of the Creative Commons Attribution license (http://creativecommons.org/licenses/by/4.0/). 